\title{
DINÁMICAS CAMPESINAS Y FITOMEJORAMIENTO PARTICIPATIVO: EL CASO DE LOS SORGOS BLANCOS (Sorghum bicolor, L. Moench) EN LA REGIÓN NORTE DE NICARAGUA ${ }^{1}$
}

\author{
Gilles Trouche ${ }^{2}$, Henri Hocdé3, Silvio Aguirre-Acuña ${ }^{4}$, Felipe Martínez-Sánchez ${ }^{5}$, Nury Gutiérrez-Palacios ${ }^{6}$
}

\begin{abstract}
RESUMEN
Dinámicas campesinas y fitomejoramiento participativo: el caso de los sorgos blancos (Sorghum bicolor, L. Moench) en la región norte de Nicaragua. En las regiones secas de Nicaragua, los sorgos blancos representan un grano básico cada vez más importante para las familias campesinas pobres. Desde 2002, el CIRAD y el CIAT manejan en colaboración con ONGs y grupos de productores experimentadores un proyecto de fitomejoramiento participativo de los sorgos dirigido a los pequeños productores. En esta publicación, los autores describen el arranque de este proyecto en el departamento de Madriz, norte de Nicaragua, e indican los resultados más originales de esta fase inicial. Ésta empezó con un diagnóstico intenso sobre los sistemas de cultivos, las variedades, los problemas de producción, los usos del sorgo y una predefinición de los objetivos de selección. Se identificaron los actores y las prácticas de la producción y los intercambios de semillas. Paralelamente, las variedades locales de sorgo tortillero y millón fueron caracterizadas morfo-agronómicamente. Como resultados, se resaltan los cambios recientes en las variedades y los sistemas de cultivo, la adopción rápida de los sorgos de ciclo corto "tortillero" mediante procesos informales de intercambios de semillas; las características notables de las variedades locales de sorgo tortillero y millón fueron cuantificadas. Estos datos sirvieron para implementar las actividades de selección participativa e identificar los progenitores y cruzamientos para los esquemas de fitomejoramiento participativo. Como perspectivas, los autores proponen insertar más este proceso de fitomejoramiento participativo en los proyectos endógenos fortaleciendo la agricultura familiar con un enfoque agroecológico y extenderlo a otros temas, cultivos y zonas en un marco interinstitucional de investigación-acción para pequeños agricultores en zonas marginales.
\end{abstract}

Palabras claves: Sorgos de grano blanco, zonas secas, innovaciones, objetivos de selección, fitomejoramiento participativo.

\begin{abstract}
Farmers dynamics and participatory plant breeding: the case of white grain sorghums in the Northern region of Nicaragua. In the dry areas of Nicaragua, white grain sorghums are an important food crop for the poor farmers. Since 2002, CIRAD and CIAT manage in collaboration with NGOs and local experimenter farmers' groups a research project on sorghum participatory breeding addressed to the low-resources farmers. In this paper, the authors describe the start of the project in the Madriz department, North of Nicaragua, and indicate the most relevant results of this preliminary phase. This work started with an intensive participatory diagnostic about the cropping systems, the varieties, the production constraints, the sorghum utilizations and a pre-definition of the breeding objectives. The participants and practices of the seed production and exchanges were identified. At the same time, the local varieties of tortillero and millón sorghum were characterized for morphological and agronomic traits. Among the results emerge the recent changes concerning the varieties and the cropping systems, the rapid adoption of the short-cycle "tortillero" sorghum by the mean of informal processes of seed exchanges; the original traits of the millón varieties, like their extreme sensitivity to photoperiod, have been quantified. These data were used for implementing the activities of participatory variety selection and for choosing the parents and crosses for the participatory breeding schemes. As perspectives, the authors propose to integrate more this process of participatory breeding within the endogenous projects strengthening the family agriculture with an agro-ecological focus and extend it to other themes, crops and areas in an inter-institutional framework of research-action for small farmers in marginal areas.
\end{abstract}

Key words: White-grain sorghum, dry areas, innovations, breeding objectives, participatory plant breeding.

1 Recibido: 4 de julio, 2006. Aceptado: 20 de setiembre, 2006.

2 Centre de coopération Internationale en Recherche Agronomique pour le Développement CIRAD - Centro Internacional de Agricultura Tropical -CIAT, AA 6713, Cali, Colombia. Correo electrónico: g.trouche@cgiar.org.

3 Centre de coopération Internationale en Recherche Agronomique pour le Développement, Département Territoires, Environnements et Acteurs, CIRAD-Tera, 73 rue Jean-Francois Breton, 34398 Montpellier Cedex 5, Francia. Correo electrónico: henri.hocde@cirad.fr

4 Centro para la Investigación, la Promoción y el desarrollo Rural y Social-CIPRES, Pueblo Nuevo, Nicaragua.

5 Hydros-Novotecni S.A., Colonia Escalón, 79 avenida norte, casa No. 422, San Salvador, El Salvador. Correo electrónico: felipe.Martinez@sginicaragua.com

6 Instituto Nicaragüense de Tecnología Agropecuaria (INTA), Centro Nacional de Investigación Agraria CNIA, km 10 Carretera Norte, Managua, Nicaragua. 


\section{INTRODUCCIÓN}

En Nicaragua el sorgo ocupa el cuarto lugar entre los granos básicos, con un área sembrado promedio de 75,000 hectáreas. Se siembran principalmente tres tipos de sorgo que son:

- Sorgo millón: sorgo de ciclo largo sensible al fotoperíodo (Cuadro 1), comúnmente cultivado en asocio con el maíz o el frijol, en sistemas manuales de bajos insumos; se utiliza para el consumo humano y animal.

- Sorgo tortillero (o sorgo blanco o maicillo): sorgo de grano blanco, de ciclo corto e insensible al fotoperíodo (Cuadro 1), introducido en la región en los años setenta pero ampliamente difundido a partir de la segunda mitad de los años ochenta. Se cultiva en diversas condiciones, desde los sistemas manuales de bajos insumos hasta los sistemas tecnificados, y se utiliza para el consumo humano y animal.
- Sorgo industrial: generalmente híbridos comerciales de ciclo corto y de grano rojo, cultivados en sistemas tecnificados mecanizados; los granos son utilizados en la fabricación de concentrados balanceados para la alimentación de los pollos y cerdos.

En las zonas más secas del país, los sorgos tortillero y millón se siembran principalmente para el consumo humano y por consecuente juegan un papel importante en la seguridad alimentaria de los pequeños productores en estas regiones desfavorecidas. Además de estos tres tipos, que ahora se distinguen en las estadísticas agrícolas nacionales, se siembran también en áreas de menor importancia, más localizadas, el sorgo escobero y en las zonas ganaderas el sorgo forrajero.

En mayo del 2002, el CIAT ${ }^{7}$ y el CIRAD 8 iniciaron un proyecto de investigación en fitomejoramiento participativo (FP) de los sorgos, dirigido a los pequeños productores de las zonas secas y pobres de

Cuadro 1. Características fisiológicas y agronómicas de los sorgos tortillero y millón de Nicaragua (Síntesis del autor a partir de los resultados del proyecto y los trabajos de Martínez 2003 y Vaksmann et al. 1996).

\begin{tabular}{|l|l|l|}
\hline \multicolumn{1}{|c|}{ Tipo } & \multicolumn{1}{|c|}{ Respuesta al fotoperíodo* } & \multicolumn{1}{c|}{ Consecuencias agronómicas } \\
\hline $\begin{array}{l}\text { Sorgo tortillero o } \\
\text { maicillo }\end{array}$ & $\begin{array}{l}\text { Insensible: la inducción de la floración no es deter- } \\
\text { minada por el fotoperíodo; la duración de la fase } \\
\text { emergencia-floración (DEF) depende solamente de } \\
\text { la suma de temperaturas disponibles. }\end{array}$ & $\begin{array}{l}\text { Es generalmente de ciclo corto: 55-65 días de la germina- } \\
\text { ción hasta floración, 85-95 días hasta madurez. Durante la } \\
\text { época lluviosa que cuenta con temperaturas casi constan- } \\
\text { tes, los ciclos a floración y madurez están estables y no va- } \\
\text { rían con la fecha de siembra. Por su ciclo corto, general- } \\
\text { mente escapa al déficit hídrico de fin de la época lluviosa } \\
\text { pero es muy susceptible a las sequías que pueden ocurrir } \\
\text { durante su fase reproductiva. }\end{array}$ \\
\hline Millón & $\begin{array}{l}\text { Sensible al fotoperíodo: necesita días cortos (me- } \\
\text { nos de 11 h 30') para que su floración se induzca; } \\
\text { la duración de la fase DEF depende de la fecha de } \\
\text { siembra y la suma de temperaturas disponibles. }\end{array}$ & $\begin{array}{l}\text { Es de ciclo largo (7-8 meses con una siembra normal en } \\
\text { mayo-junio) y se cosecha entre diciembre y enero. Cual- } \\
\text { quiera sea la fecha de siembra (temprana o atrasada en pri- } \\
\text { mera o en postrera), florecerá siempre entre final de octu- } \\
\text { bre y el 15 de noviembre. Esta época de floración coincide } \\
\text { con las últimas lluvias del invierno, cuando todavía hay } \\
\text { agua disponible en el suelo. Por su fotoperiodismo y su sis- } \\
\text { tema radicular muy profundo, es muy resistente a las se- } \\
\text { quías en todas las fases de desarrollo, excepto en el estado } \\
\text { plántula. El millón se puede sembrar muy temprano, cuan- } \\
\text { do llegan las primeras lluvias; consecuentemente su cober- } \\
\text { tura contribuye a proteger los suelos de laderas de la ero- } \\
\text { sión, asimismo las plantas de millón aprovechan bien la } \\
\text { mineralización biológica de la materia orgánica }\end{array}$ \\
\hline
\end{tabular}

* Duración diaria de la luz expresada en horas o tiempo de horas de luz.

7 CIAT: Centro Internacional de Agricultura Tropical.

8 CIRAD: Centre de Coopération Internationale en Recherche Agronomique pour le Développement-Francia. 
Nicaragua. Entre las tres zonas de intervención del proyecto, se escogió el departamento de Madriz, ubicado en el norte del país, por ser uno de los más áridos con un alto grado de pobreza, con predominio de los pequeños productores, y por supuesto por ser productor importante de sorgo blanco (5590 ha, $10 \%$ del área sembrado en el país) (Datos del ciclo agrícola 2000-2001 del III CENAGRO, INEC 2002). Para empezar el proyecto en esta zona, debido a la poca información disponible sobre este rubro y al carácter pionero de esta investigación, el equipo de investigación decidió realizar un diagnóstico intenso abarcando los temas siguientes: condiciones y problemas de producción de los diferentes tipos de sorgo, usos de la producción, origen, diversidad y características de las variedades actuales y antiguas, prácticas de producción e intercambio de las semillas, entre otros. Al final se pretendía identificar con los agricultores los tipos de sorgo a mejorar y los objetivos y prioridades de mejoramiento de éstos en la zona; sobre esta base se planeó y se inició el trabajo de fitomejoramiento participativo (Figura 1). El objetivo del presente trabajo es presentar una síntesis de los resultados originales obtenidos en la fase de diagnóstico del proyecto y examinar en qué grado esta información específica, orientó las actividades de fitomejoramiento participativo de los sorgos tortillero y millón, así como la futura difusión de las variedades generadas.

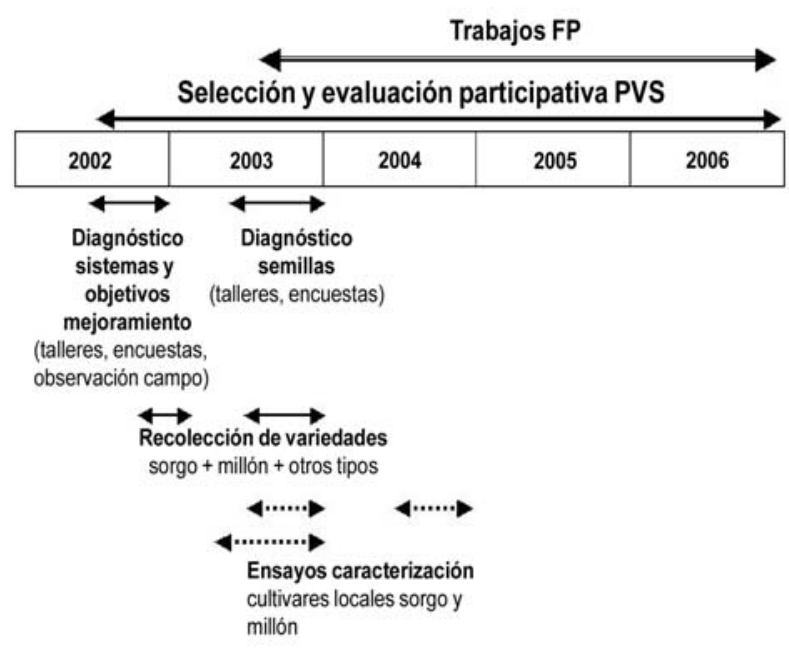

Figura 1. Esquema de las etapas de implementación del proyecto Fitomejoramiento Participativo en sorgo, Nicaragua.
Este artículo es parte de un conjunto de varias publicaciones que presentan la experiencia y los resultados del proyecto FP sorgo y arroz en Nicaragua (Hocdé 2006; Lhomme 2005; Trouche et al. 2006).

\section{MATERIALES Y MÉTODOS}

\section{Descripción de la zona de estudio}

El departamento de Madriz se encuentra ubicado en la región norte de Nicaragua (Figura 2) entre los grados $13^{\circ} 15^{\prime}$ y $13^{\circ} 40^{\prime}$ de latitud norte y $86^{\circ} 05^{\prime}$ y $86^{\circ}$ $45^{\prime}$ de longitud oeste. Tiene un relieve accidentado conformado con laderas, valles y llanos con un rango de altitud entre 400 y $1.490 \mathrm{msnm}$. El departamento pertenece a la franja seca de Nicaragua (trópico-seco) y cuenta con precipitaciones anuales entre $650-800$ mm para los municipios más secos y 1.200-1.400 mm para los más lluviosos. La estación lluviosa se extiende de la última decada de mayo hasta la primera decada de noviembre, definiendo dos épocas de cultivo, la primera y la postrera, separadas por un periodo seco entre el 15 de julio y el 15 de agosto conocido como canícula o veranillo. En el municipio de Somoto, la canícula es calificada de severa con precipitaciones menores a $75 \mathrm{~mm}$ en 5 años entre 10 (Martínez 2003). Además, el regimen de lluvia se caracteriza por la irregularid de las precipitaciones dentro de cada época de cultivo, dado que se presentan a menudo tres pentadas consecutivas sin lluvia (Rapidel y Rodríguez 2000). Madriz está catalogado como uno de los departamentos más pobres del país. La actividad económica más importante es la agricultura, principalmente la producción de granos básicos como maíz, frijol y sorgo. El $81 \%$ de las fincas se pueden calificar de pequeñas $(<$ $3,5 \mathrm{ha})$ o medianas (3,5-14 ha) y producen granos básicos destinados al autoconsumo y la venta en los mercados locales. Por las características de las fincas y la topografía, la siembra de sorgo industrial es casi inexistente; considerando el área sembrada así como la producción, el sorgo tortillero ahora predomina sobre el millón (60\% versus $40 \%)$.

\section{Diagnósticos}

Entre junio y noviembre del 2002, en el marco de su tesis de maestría en agronomía, Felipe Martínez 


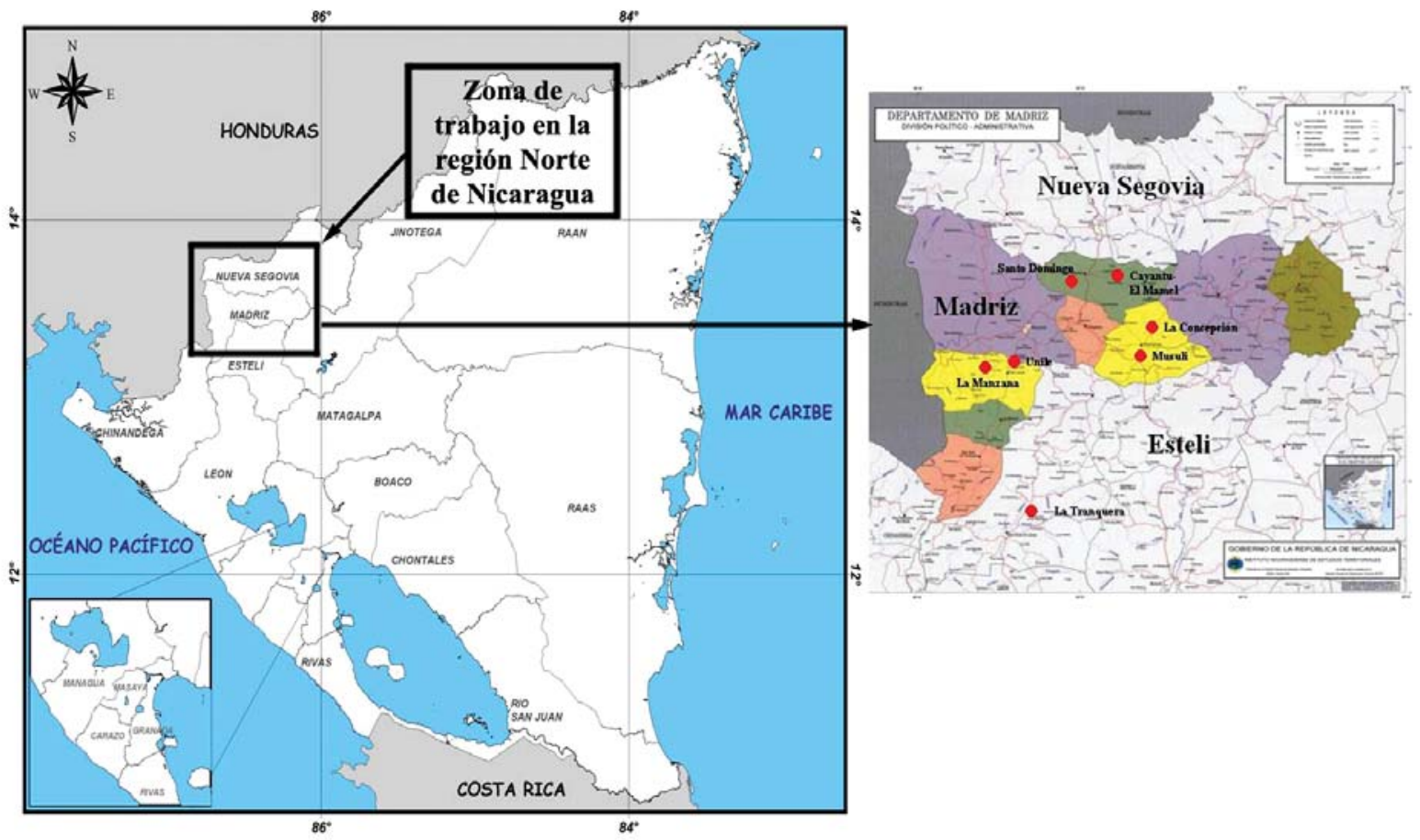

Figura 2. Zona y localidades de trabajo del proyecto FP sorgo en la región Norte de Nicaragua.

realizó un diagnóstico formal sobre los sistemas de cultivo de sorgo en cuatro localidades representativas de la diversidad de las condiciones de producción de los sorgos en el departamento de Madriz (Martínez 2003). Este diagnóstico se desarrolló en seis etapas conforme a la metodología descrita a continuación:

- Revisión de literatura y contactos con las instituciones locales para una preselección de los sitios de estudio.

- Visita de las comunidades preseleccionadas para hacer una selección final.

- Taller público en cada comunidad con 20-30 productores y productoras: presentación del estudio a realizar y los objetivos del proyecto FP, diagnóstico participativo para describir la comunidad y sus agricultores así mismo como la historia y la situación actual del cultivo de sorgo (sistemas de cultivo, variedades actuales y abandonadas, usos y limitantes de la producción). Para este propósito, se utilizaron herramientas como el mapeo de los recursos naturales y usos de los suelos en la comunidad, la línea del tiempo, los inventarios de variedades y prácticas, y la tipología de los agricultores de la comunidad. Al final del taller, se estableció la lista de los productores a entrevistar en la siguiente etapa. También se organizó con los productores participantes una recolecta de semillas de las variedades de sorgo cultivadas en la comunidad.

- Entrevistas a productores(as) con un cuestionario semi-abierto (10-12 agricultores por comunidad) y observaciones en campo.

- Procesamiento y análisis de los datos de las entrevistas.

- Taller de retro-información y discusión de los resultados del estudio en cada comunidad para su validación.

Para verificar los objetivos de mejoramiento indicados por los productores durante el diagnóstico formal y definir los criterios de selección con más precisión, también identificar variedades interesantes y/o progenitores para los futuros cruzamientos, se establecieron en 2002 y en 2003 ensayos de prueba de nuevas variedades y líneas avanzadas. 
Un año después, entre junio y diciembre del 2003, otros dos estudiantes ${ }^{9}$ llevaron a cabo un estudio para complementar y ampliar a nivel geográfico el trabajo anterior, con un enfoque en la comprensión de los mecanismos y actores involucrados en la producción, los intercambios y la difusión de semillas de sorgo en la región (Plessis 2004). También ellos complementaron la recolecta de las variedades locales y realizaron una caracterización preliminar de éstas. Dicho estudio se realizó en seis comunidades (tres incluidas en el estudio de 2002 y tres nuevas). Para realizar los talleres públicos en las tres comunidades nuevas, se aplicó la misma metodología utilizada por F. Martínez en 2002. A continuación de los talleres, en cada comunidad, 1012 productores (as) fueron entrevistados entre septiembre y octubre de 2003.

\section{Caracterización de las variedades locales recolectadas}

Para realizar estos trabajos de caracterización fenotípica, los protocolos experimentales aplicados fueron los siguientes:

1. Caracterización agromorfológica y fisiológica de 11 variedades locales de millón y tres variedades africanas sensibles al fotoperíodo: experimento realizado en la estación experimental del CNIA, Managua entre mayo de 2003 y enero de 2004. Diseño de campo en parcelas subdivididas (splitplot) con tres fechas de siembra en parcelas grandes (30 de mayo, 4 de julio y 2 de septiembre) y los 14 genotipos en parcelas pequeñas (Cuadro 2), con cuatro repeticiones; las parcelas elementales fueron de dos surcos de seis metros de largo. Se midieron 15 variables (Gutiérrez 2004). Para los análisis estadísticos de los datos, se utilizaron los software Mstatc (análisis bi-factorial) y Xlstat (análisis por fecha). Para la separación de las medias, se utilizó la prueba de Newman-Keuls al 5\%.

2. Descripción de 41 variedades locales de sorgo tortillero en comparación a cinco variedades mejoradas testigo: ensayo realizado en parcela campesina en Somoto entre septiembre y diciembre de 2003 (postrera). Diseño sin repetición, parcelas experimentales de dos surcos de cinco metros de largo

9 Justine Plessis, estudiante de l'ISTOM, Cergy-Pontoise Francia y Jairo Izaguirre, estudiante de la UCATSE, Estelí Nicaragua.
Cuadro 2. Nombre y origen de las variedades de millón recolectadas en el año 2002 en Madriz, Nicaragua y caracterizadas en el año 2003.

\begin{tabular}{crll}
\hline $\begin{array}{c}\text { Número } \\
\text { ensayo }\end{array}$ & $\begin{array}{c}\text { Número } \\
\text { colección }\end{array}$ & \multicolumn{1}{c}{ Variedad } & \multicolumn{1}{c}{ Origen } \\
\hline 1 & 4 & Riñón & Sto Domingo Totogalpa \\
2 & 5 & Mano de piedra & $\begin{array}{l}\text { Sto Domingo Totogalpa } \\
\text { Cayantu Totogalpa }\end{array}$ \\
3 & 12 & Indio & Cayantu Totogalpa \\
4 & 9 & Amarillo & Cayantu Totogalpa \\
5 & $10 \mathrm{~b}$ & Salvadoreño & Tortillero temprano Cayantu Totogalpa \\
6 & 18 & Estopa Negra & Cuje, Totogalpa \\
7 & 1 & Guansapo & Unile Somoto \\
8 & 24 & Santa Cruz & La Manzana San Lucas \\
9 & $21 \mathrm{a}$ & Colapanda & La Manzana San Lucas \\
10 & 22 & Maicillón ligero & Sto Domingo Totogalpa \\
11 & 2 & Souroukoukou & Mali \\
12 & & Wassoulou & Mali \\
13 & & G 1581 & Camerún \\
14 & &
\end{tabular}

por variedad, diez variables morfológicas medidas.

3. Caracterización de 35 variedades locales de sorgo tortillero (32 comunes con el estudio de 2003) y tres variedades testigo (Cuadro 3): ensayo realizado en parcela campesina en Palacagüina entre septiembre y diciembre de 2004 (Postrera). Diseño en Bloques Completos al Azar con tres repeticiones, parcelas experimentales de dos surcos de cinco metros de largo, 18 variables medidas. El análisis de clasificación jerárquica se realizó con base en 12 variables cuantitativas y dos variables cualitativas transformadas en binarias (compactación de las panojas y pigmentación de las plantas) con el software Xlstat 13.3, utilizando la distancia euclidiana y el método de Ward como criterio de agregación.

\section{RESULTADOS}

\section{Diversidad de los sistemas de cultivo a base de sorgo}

En su estudio realizado en 2002, F. Martínez (2003) identificó en cuatros localidades de Madriz doce sistemas de cultivo principales, entre los cuales solo dos no incluyen algún tipo de sorgo (Figura 3). Cinco sistemas de cultivo incluyen el sorgo millón, cuatro con una siembra en primera y uno con una siembra 
Cuadro 3. Nombre local y origen de las variedades de sorgo tortillero recolectadas entre 2002 y 2003 en Madriz y Limay, Nicaragua y caracterizadas en el año 2004.

\begin{tabular}{|c|c|c|c|c|c|c|c|}
\hline $\begin{array}{l}\text { Número } \\
\text { entrada }\end{array}$ & $\begin{array}{l}\text { Número de } \\
\text { recolecta }\end{array}$ & $\begin{array}{l}\text { Nombre local de } \\
\text { la variedad** }\end{array}$ & $\begin{array}{c}\text { Comunidad de } \\
\text { origen } * * *\end{array}$ & $\begin{array}{l}\text { Número } \\
\text { entrada }\end{array}$ & $\begin{array}{l}\text { Número de } \\
\text { recolecta }\end{array}$ & $\begin{array}{c}\text { Nombre } \\
\text { local variedad }\end{array}$ & $\begin{array}{c}\text { Comunidad de } \\
\text { origen }\end{array}$ \\
\hline 1 & 7 & Tortillero E rosada & St Domingo & 21 & 58 & Tortillero precoz & Concepción \\
\hline 2 & 16 & Blanco & Cayantu & 22 & 59 & Amarillo crema & Tranquera \\
\hline 3 & 17 & Amarillo & Cayantu & 23 & 60 & Tortillero & Musuli \\
\hline 4 & 19 & Guatemala & La Manzana & 24 & 61 & Tortillero & Musuli \\
\hline 5 & 20 & Tortillero chelito & La Manzana & 25 & 63 & S. tortillero & Musuli \\
\hline 6 & 25 & Tortillero & Uniles & 26 & 65 & Amarillo $1 / 2$ alto & Cayantu \\
\hline 7 & 29 & Ligero & St Domingo & 27 & 66 & Blanco tortillero & Cayantu \\
\hline 8 & 30 & Estopa negra & La Manzana & 28 & 67 & Tortillero & Cayantu \\
\hline 9 & $31^{\mathrm{a}}$ & Tortillero & St Domingo & 29 & 68 & Tortillero & Cayantu \\
\hline 10 & 32 & S. tortillero & St Domingo & 30 & 70 & Tortillero & La Manzana \\
\hline 11 & 34 & Estopa negra & La Manzana & 31 & 73 & Tortillero precoz & Uniles \\
\hline 12 & 37 & Tortillero & St Domingo & 32 & 74 & Tortillero E blanca & Uniles \\
\hline 13 & 40 & Tortillero & St Domingo & 33 & 75 & Blanco alto & Cayantu \\
\hline 14 & 41 & Sorgo & St Domingo & 34 & 76 & Carta Blanca & Sn Dionisio \\
\hline 15 & 45 & Tortillero pinolero & St Domingo St & 35 & 77 & Crema & Limay \\
\hline 16 & 46 & Tortillero & Domingo & & & & \\
\hline 17 & 47 & Tortillero & St Domingo & $\mathrm{T} 1$ & & Tortillero precoz & INTA/CIRAD \\
\hline 18 & 50 & Tortillero & St Domingo & $\mathrm{T} 2$ & & INTA Ligero & INTA \\
\hline 19 & 56 & Tortillero & Concepción & $\mathrm{T} 3$ & & Pinolero 1 & INTA \\
\hline 20 & 57 & Tortillero & Concepción & & & & \\
\hline
\end{tabular}

* En negrilla las variedades comunes en los dos estudios de 2003 y 2004.

** $\mathrm{E}=$ estopa (gluma); *** $\mathrm{St}=$ Santo

tardía en postrera (millón para forraje). Cinco sistemas diferentes incluyen el sorgo de tipo tortillero: dos sistemas buscan dos cosechas al año, con una siembra en primera que da una primera cosecha de grano en septiembre, seguida de un corte del rastrojo para favorecer el retoño y una segunda cosecha en diciembre. Entre los diez sistemas incluyendo el sorgo, solo cuatro son sistemas de monocultivo de millón o sorgo tortillero, siendo los demás asocios de dos, tres o cuatro cultivos. Entre los sistemas reportados, lo más común fue el sorgo tortillero sembrado en postrera.

Para cada sistema de cultivo, se aplican diferentes formas y arreglos de siembra, los cuales están determinados principalmente por la estructura física de los suelos y la topografía (pendiente) y por los recursos económicos y equipamientos de los productores. Así en la comunidad de Unile (Somoto) los terrenos planos permiten el uso del arado egipcio y la siembra en surcos; caso contrario se encuentra en la comunidad de Cayantu (Totogalpa) donde por su topografía muy escarpada, no hay trabajo del suelo y se siembra sólo al espeque.
Una síntesis de las formas y arreglos de siembra utilizados en los principales sistemas de cultivo incluyendo el sorgo se presenta en el Cuadro 4.

Las labores culturales, entre las cuales la más importante para el éxito de la cosecha es el control de malezas, dependen del arreglo de siembra aplicado.

\section{Diversidad de utilización de los sorgos}

El principal empleo del grano de los sorgos blanco, millón o tortillero, es el consumo familiar en forma de tortilla; también juega un papel importante en la alimentación de las aves de corral y cerdos de la finca, que son los suplidores de las proteínas animales.

El destino del sorgo en las comunidades de descendencia indígena (Cayantu y Santo Domingo de Totogalpa), es el autoconsumo y solamente pequeñas cantidades son vendidas (Cuadro 5). Es diferente en 


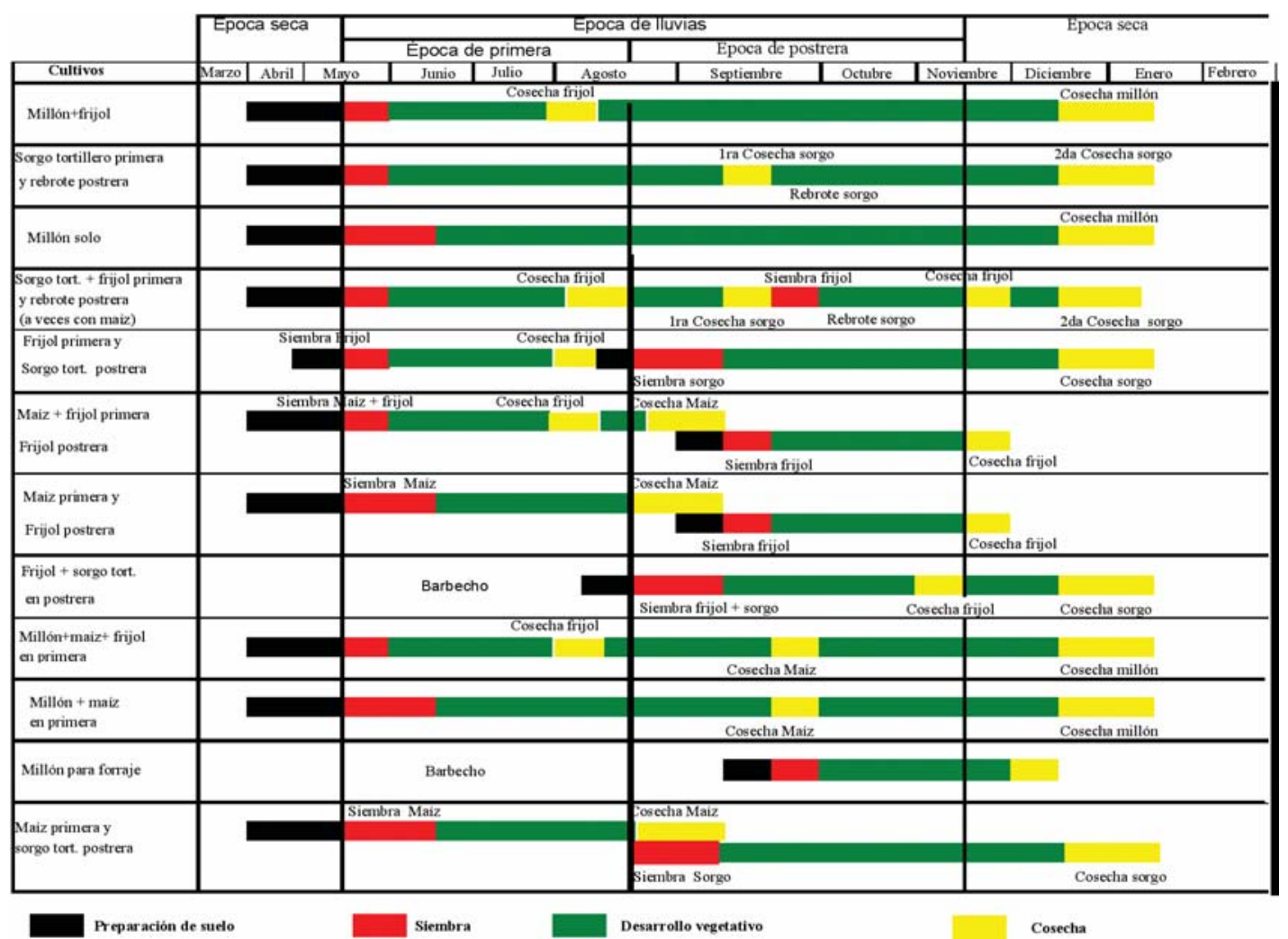

Figura 3. Sistemas de cultivo identificados en Madriz, Nicaragua (Martínez 2003).

Cuadro 4. Forma y arreglos de siembra aplicados en los principales sistemas de siembra de sorgo en cuatro sitios de Madriz, Nicaragua (Martínez 2003).

\begin{tabular}{|l|l|l|l|}
\hline \multicolumn{1}{|c|}{ Sistema } & Forma de siembra & \multicolumn{1}{|c|}{ Arreglos más utilizados } & $\begin{array}{l}\text { Contexto físico y socio- } \\
\text { económico de aplicación }\end{array}$ \\
\hline Millón + maíz (primera) & Espeque & $\begin{array}{l}\text { Golpe a golpe: golpes de maíz alternados } \\
\text { con los golpes de millón en el mismo surco }\end{array}$ & $\begin{array}{l}\text { Pendientes, comunidad } \\
\text { indígena }\end{array}$ \\
\hline $\begin{array}{l}\text { Millón o sorgo tortillero + } \\
\text { frijol (primera o postrera) }\end{array}$ & $\begin{array}{l}\text { Espeque o a } \\
\text { chorrillo }\end{array}$ & $\begin{array}{l}\text { Callejoniado y al tramo: frijol sembrado } \\
\text { en un callejón de dos o tres surcos entre } \\
\text { dos surcos de millón, sorgo o maíz, éstos } \\
\text { solos o asociados }\end{array}$ & $\begin{array}{l}\text { Pendientes y planos, } \\
\text { productores con } \\
\text { limitación de terreno }\end{array}$ \\
\hline $\begin{array}{l}\text { Sorgo escobero + millón o sorgo } \\
\text { tortillero (primera o postrera) }\end{array}$ & Espeque & $\begin{array}{l}\text { Niztamaliado: diversas plantas en mismo } \\
\text { golpe }\end{array}$ & Pendientes y planos \\
\hline $\begin{array}{l}\text { 1. Sorgo tortillero solo (para } \\
\text { producción de grano y forraje) } \\
\begin{array}{l}\text { 2. Millón en postrera para } \\
\text { forraje }\end{array}\end{array}$ & $\begin{array}{l}\text { A chorrillo con arado } \\
\text { de bueyes }\end{array}$ & $\begin{array}{l}\text { Surcos seguidos: se siembra en cada } \\
\text { surco “abierto" por el arado }\end{array}$ & $\begin{array}{l}\text { Planos o ligeramente } \\
\text { ondulados }\end{array}$ \\
\hline $\begin{array}{l}\text { 1. Sorgo tortillero solo } \\
\text { 2. Millón solo en primera para } \\
\text { grano }\end{array}$ & $\begin{array}{l}\text { A chorrillo con arado } \\
\text { de bueyes }\end{array}$ & $\begin{array}{l}\text { Surcos de por medio: se deja un surco } \\
\text { libre "muerto" entre cada surco abierto } \\
\text { por el arado }\end{array}$ & $\begin{array}{l}\text { Planos o ligeramente } \\
\text { ondulados }\end{array}$ \\
\hline
\end{tabular}


las comunidades de Unile y La Manzana, de población mestiza, donde la venta del sorgo tortillero es señalada como importante (Cuadro 5); ésto denota una lógica más comercial de los productores, donde incluso se almacena el grano para pagar la mano de obra contratada temporalmente.

Cuadro 5. Utilización de la producción de sorgo en cinco localidades de Madriz, Nicaragua (Martínez 2003).

\begin{tabular}{lcccc}
\hline \multicolumn{1}{c}{$\begin{array}{c}\text { Utilización } \\
\text { del grano }\end{array}$} & Cayantu $^{1}$ & $\begin{array}{c}\text { Sto } \\
\text { Domingo }\end{array}$ & Unile $^{1}$ & $\begin{array}{c}\text { La } \\
\text { Manzana1 }\end{array}$ \\
\hline $\begin{array}{l}\text { Tortilla y } \\
\text { otros platos }\end{array}$ & $100 \%$ & $100 \%$ & $72 \%$ & $100 \%$ \\
$\begin{array}{l}\text { Alimento aves } \\
\text { y cerdos }\end{array}$ & $100 \%$ & $60 \%$ & $100 \%$ & $80 \%$ \\
Venta & $50 \% *$ & $40 \% *$ & $72 \%$ & $70 \%$ \\
Pago mano obra & - & - & $16 \%$ & $20 \%$ \\
\hline
\end{tabular}

${ }^{1}$ Porcentaje de los agricultores (as) dedicando su producción de grano de sorgo para este propósito.

* Se venden pequeñas cantidades.

Además de la tortilla, los granos de sorgo se usan para elaborar diferentes platos y bebidas. Algunos son específicos del tipo de sorgo: con el millón elaboran la chicha, alborotos, concentrados para animales, y con el sorgo tortillero, rosquetes, nacatamal, atolillo, entre otros. En su estudio, Martínez (2003) reporta que algunas mujeres mencionan que en comparación al millón, los granos de sorgo tortillero necesitan más tiempo de cocción (y por lo tanto mayor cantidad de leña) y dan menos tortillas para una misma cantidad de grano ("millón es más rendidor en tortilla").

Con respecto al sabor de la tortilla, la referencia es siempre la tortilla de maíz blanco con una preferencia siempre a su favor. Al profundizar entre las tortillas de los diferentes tipos y variedades de sorgo, el color, la textura y la presentación son criterios determinantes, los productores entrevistados prefieren la tortilla de sorgo tortillero, por ser más blanca que la de millón ${ }^{10}$ y aseguran que en sabor no existe gran

10 Antes, un campesino nunca decía que consumía tortilla de sorgo porque era admitir que era pobre. Ahora ya no es vergüenza para él comentar las diferencias de calidad de las tortillas de sorgo. ¿Será también una prueba que la calidad de la tortilla de sorgo mejoró? ¿Hasta qué punto el sorgo cambió de estatus en la mente de los campesinos? Todavía las poblaciones urbanas tienen esta imagen negativa del sorgo para el consumo humano. diferencia. Sin embargo, en pruebas culinarias posteriores evaluando varias variedades con diferentes calidades de grano, los agricultores catadores pudieron identificar diferencias importantes de sabor.

Otro producto importante del sorgo es el rastrojo o la planta entera utilizada como forraje. La importancia de su utilización depende de la presencia de ganado mayor en la finca; en las comunidades con menor presencia de animales el rastrojo se utiliza más para la incorporación al suelo. En esta región de Nicaragua, los agricultores lo llaman guate o rastrojo, según si se recolecta en la parcela o no. El guate representa los restos de las plantas una vez cortadas las panículas a madurez, o la planta entera en el caso de la siembra del millón en octubre, que son recolectados secos y trasladados a la casa para conservarlos en montón colocado encima de un techo o en manojos en las condiciones ambientales normales; el guate se suministra a los animales, generalmente sin ningún aditivo, entre los meses de febrero y mayo (época seca) mientras se recuperan los pastizales; son pocos los agricultores que pican este guate en trozos pequeños. El "rastrojo" representa los mismos restos de las plantas después de la cosecha de grano, pero se quedan en la parcela y los animales se alimentan de éstos mediante el pastoreo. En las comunidades con mejor comunicación vial, los productores elaboran pequeños manojos de guate de cinco libras que luego son vendidos a los ganaderos en la época seca.

\section{La diversidad de variedades}

Inventario de las variedades de millón y tortillero (Plessis 2004) 11

En la actualidad, los agricultores de esta región siembran todavía una docena ${ }^{12}$ de variedades locales de millón (Figura 4). Varios cultivares son calificados por los productores como rústicos por su adaptación a suelos pobres de laderas, a un manejo mínimo (sin fertilizante, una sola deshierba) y por una alta tolerancia a la sequía. El millón indio o lerdo es la variedad más

11 Resultados de las entrevistas de 62 productores (48 hombres y 14 mjujres) entre septiembre y octubre 2003 en las seis comunidades estudiadas por J. Plessis y J. Izaguirre.

12 En total se reportaron entre 13 y 15 variedades de millón (algunas identificaciones de variedades causan problemas), tres de estas han desaparecido de la zona según los productores. 


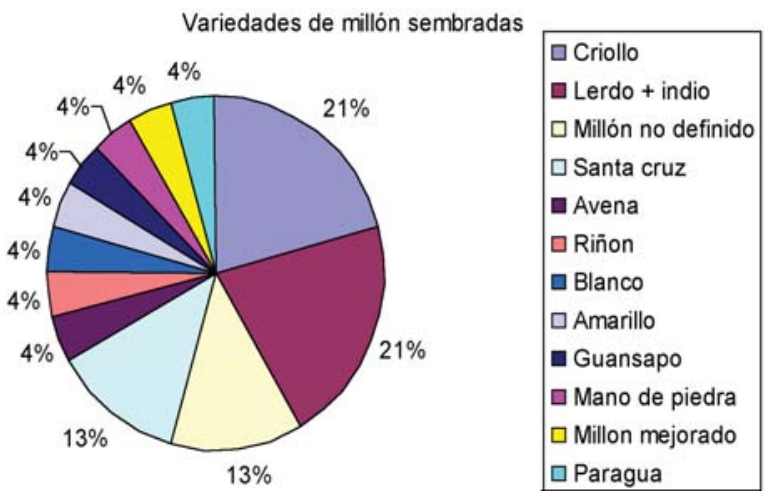

Figura 4. Las variedades de millón cultivadas en Madriz y Limay, Nicaragua (Plessis 2004).

antigua en la región, se caracteriza por ser tardía y tener rendimientos bastante bajos (menos de 1,5 t/ha). En general, los nombres de algunas variedades se refieren a la forma de la panoja (riñón, mano de piedra), del pedúnculo (encorvado en Paragua o Colapanda) o al color y forma de grano (blanco, amarillo, avena). Actualmente, fuera del conjunto de variedades calificadas indio o lerdo o criollo, la variedad más sembrada en la región de Estelí y Madriz es la variedad Santa Cruz (Martínez 2003).

Solamente $3 \%$ de los agricultores declaran cultivar varias variedades de sorgo tortillero al mismo momento. Casi $75 \%$ de los productores siembran una variedad llamada «Tortillero»; en realidad este calificativo no identifica una variedad precisa sino que define más que todo una variedad con granos blancos no manchados y glumas claras (plantas canelas) cuyos granos sirven para elaborar tortillas de calidad. Además, fueron reportadas variedades llamadas Sorgo Estopa Negra, Sorgo Crema, Pinolero, Sorgo Ligero, Sorgo Blanco Alto, Sorgo Amarillo, Sorgo Guatemala y Tortillero Precoz (IRAT 204) ${ }^{13}$. La variedad Crema

\footnotetext{
13 Los agricultores de las seis localidades estudiadas enumeraron 23 variedades de sorgo tortillero, introducidas por diferentes instituciones o productores y sembradas durante algún tiempo en su comunidad; indicaron que 12 de estás habían desaparecidas (pérdida de semilla por sequía) o habían sido abandonadas (por baja productividad o mala calidad de grano).
}

se encuentra solamente en el valle de San Juan de Limay donde ocupa casi todo el área en sorgo.

Caracterización morfológica y agronómica de las variedades de millón y sorgo tortillero recolectadas

Del trabajo de caracterización fisio-morfoagronómica de 11 variedades locales de sorgo millón en tres fechas de siembra, comparados a tres variedades africanas sensibles al fotoperíodo, los resultados más sobresalientes fueron los siguientes (Cuadro 6):

- A pesar que se recolectaron en la misma latitud en localidades que tienen condiciones pluviométricas bastante similares, existe una variación significativa en las fechas de floración y madurez fisiológica entre las variedades locales estudiadas (rango de variación de 15 días para la fecha de floración y 20 días para la fecha de madurez fisiológica). La variedad Santa Cruz es la más precoz en floración mientras Salvadoreño y Estopa Negra son las tardías; en comparación las tres variedades africanas probadas son más precoces, florecen casi dos semanas antes del millón Santa Cruz, en el caso de Souroukoukou y G 1581 (Gutiérrez 2004).

- Los sorgos millón de Nicaragua son extremadamente sensibles al fotoperíodo: sembrados en dos fechas separadas de 36 días (30 de mayo y 4 de julio), despliegan su hoja bandera y luego florecen casi el mismo día, ésto es indicado por los valores muy cerca de 1 del coeficiente de respuesta al fotoperíodo $\mathrm{Kp}^{14}$. Estos sorgos millones responden de manera más fina a los cambios de fotoperíodo que las variedades africanas Souroukoukou y Wassoulou (Gutiérrez 2004), esta última siendo clasificada entre las más fotoperiódicas en Mali (Chantereau et al. 1998).

- En altura de planta, Souroukoukou se diferencia significativamente de las demás variedades, siendo la única de porte más bajo.

\footnotetext{
14 Razón entre la reducción de duración de la fase germinacióndespliegue de la hoja bandeja entre dos fechas de siembra y la diferencia de tiempo entre las dos fechas, estas duraciones se calculan en suma de temperaturas medianas.
} 
Cuadro 6. Descripción morfo-fisiológica de 11 cultivares locales de millón y tres variedades africanas sensibles al fotoperíodo. Madriz, Nicaragua. 2006.

\begin{tabular}{|c|c|c|c|c|c|c|c|c|c|}
\hline Variedades & $\begin{array}{c}\text { Fecha } \\
\text { floración } 1\end{array}$ & $\mathbf{K} \mathbf{p}^{2}$ & $\begin{array}{c}\text { Número } \\
\text { hojas }^{1}\end{array}$ & $\begin{array}{c}\text { Altura } \\
\text { planta }^{3} \\
(\mathbf{c m})\end{array}$ & $\begin{array}{l}\text { Compacta- } \\
\text { ción de la } \\
\text { panoja }\end{array}$ & $\begin{array}{c}\text { Rendimiento } \\
\text { grano }^{3} \\
(\mathrm{~kg} / \mathrm{ha})\end{array}$ & $\begin{array}{l}\text { Indice de } \\
\text { cosecha }^{3,4}\end{array}$ & $\begin{array}{c}\text { Peso } 1000 \\
\operatorname{granos}^{3}(g)\end{array}$ & $\begin{array}{c}\text { Número } \\
\text { granos por } \\
\text { panoja }^{3}\end{array}$ \\
\hline Riñon & 23 nov. $b^{5}$ & 1,09 & 35 & $489 \mathrm{ab}$ & Abierta & 2.468 & 7 & $25 \mathrm{~d}$ & 1.882 \\
\hline Mano de piedra & 18 nov. bc & 0,98 & 35 & $448 \mathrm{~b}$ & Cerrada & 2.538 & 13 & $28 \mathrm{~cd}$ & 1.735 \\
\hline Indio & 20 nov. bc & 1 & 34 & $476 a b$ & Cerrada & 2.838 & 7 & $24 \mathrm{~d}$ & 2.198 \\
\hline Amarillo & 20 nov. bc & 1 & 34 & $457 \mathrm{~b}$ & Semi cerrada & 2.485 & 11 & $23 \mathrm{~d}$ & 2.021 \\
\hline Salvadoreño & 29 nov. a & 1,07 & 36 & $503 \mathrm{ab}$ & Semi cerrada & 1.467 & 3 & $24 \mathrm{~d}$ & 1.164 \\
\hline Tortillero temprano & 19 nov. bc & 0,98 & 34 & $501 \mathrm{ab}$ & Semi cerrada & 2.565 & 7 & $24 \mathrm{~d}$ & 1.978 \\
\hline Estopa Negra & 29 nov. a & 0,99 & 36 & $431 \mathrm{~b}$ & Semi cerrada & 2.582 & 8 & $23 \mathrm{~d}$ & 2.143 \\
\hline Guansapo & 20 nov. bc & 0,98 & 35 & $458 \mathrm{~b}$ & Semi cerrada & 1.773 & 5 & $24 \mathrm{~d}$ & 1.380 \\
\hline Santa Cruz & 14 nov. cd & 0,96 & 36 & $502 \mathrm{ab}$ & Cerrada & 2.760 & 9 & $27 \mathrm{~d}$ & 1.957 \\
\hline Colapanda & 22 nov. b & 0,98 & 34 & $453 \mathrm{~b}$ & Semi cerrada & 2.562 & 10 & $28 \mathrm{~cd}$ & 1.760 \\
\hline Maicillón ligero & 23 nov. b & 1,06 & 35 & $503 \mathrm{ab}$ & I & 2.462 & 6 & $26 \mathrm{~d}$ & 1.802 \\
\hline Souroukoukou & 28 oct. e & 0,85 & 33 & $326 \mathrm{c}$ & Cerrada & 3.138 & 22 & $31 \mathrm{c}$ & 1.898 \\
\hline Wassoulou & 12 nov. $\mathrm{d}$ & 0,95 & 33 & $542 \mathrm{a}$ & Abierta & 2.569 & 14 & $34 \mathrm{~b}$ & 1.410 \\
\hline G 1581 & 1 nov. e & 0,91 & 33 & $505 \mathrm{ab}$ & Semi cerrada & 3.459 & 11 & $54 \mathrm{a}$ & 1.213 \\
\hline Media & 22 nov. & & 38 & 471 & & 2546 & 9,4 & 28 & 1.753 \\
\hline $\mathrm{CV}$ & 1,8 & & 4,7 & 6,5 & & 20.0 & 17,9 & 7,7 & 22,0 \\
\hline F var & $34.6 * *$ & & $1,9 \mathrm{Ns}$ & $11,3 * *$ & & $3,7 * *$ & $16 * *$ & $55^{* *}$ & $3 * *$ \\
\hline $\mathrm{Se}$ & 2,2 & & 1,3 & 21,6 & & 361 & 1,2 & 1,5 & 273 \\
\hline
\end{tabular}

1 Resultados con la fecha de siembra del 30 de mayo.

$2 \mathrm{Kp}$ : coeficiente de fotoperiodismo que varía de 0 (insensible) a 1 (fuertemente fotosensible).

3 Resultados para la fecha de siembra del 4 de julio.

4 Índice de cosecha IC= (biomasa económica (grano)/biomasa total de la planta) x 100 (Paul 1990).

5 Los tratamientos con la misma letra no son significativamente diferentes según la prueba de separación de media de Newsman-Keuls al 5\%. Ns, ** : Valor de F no significativo y significativo al $1 \%$, respectivamente.

- G 1581 y Souroukoukou fueron las más productivas sobre todo por efecto del componente peso de 1.000 granos, ya que superaron significativamente a las otras variedades;

- Con respecto al índice de cosecha, Souroukoukou fue significativamente superior a todas las otras variedades.

En el primer estudio de caracterización morfológica de 41 cultivares locales de sorgo tortillero conducido en 2003 (Plessis 2004), se determinó que 32 de los cultivares recolectados en la zona de estudio (seis localidades mencionadas anteriormente) fueron diferentes de las dos variedades oficialmente liberadas en la región por el INTA (Tortillero Precoz y Pinolero 1) y de las otras tres variedades ampliamente difundidas en los países vecinos e introducidas en esta región de Nicaragua por instituciones gubernamentales u ONG (Sureño, CENTA S-2 y Dorado). Entre los 38 cultivares descritos a madurez, identificamos tres veces el CENTA
S-2 (llamado por los productores "Sorgo Estopa Negra") y una sola vez Dorado (con el nombre "Chacopan"), Tortillero Precoz y Pinolero.

En el segundo trabajo de caracterización agro morfológica de 35 cultivares locales de sorgo tortillero y tres variedades testigo INTA, el análisis de clasificación jerárquica realizada, estructura los 38 cultivares estudiados en seis grupos bien identificados (Figura 5); entre éstos, solo dos grupos (ubicados en la extrema derecha del dendrograma) con un total de seis cultivares, reúnen las variedades mejoradas de INTA y los cultivares probablemente derivadas de éstas:

- Grupo de cultivares emparentados a Pinolero 1, caracterizados por un ciclo largo, altura de planta de $1,7 \mathrm{~m}$, panojas alargadas, granos pequeños $\mathrm{y}$ bajos rendimientos (en las condiciones del ensayo sufrieron de estrés hídrico): cultivares 9 y 10 más la variedad original Pinolero 1. 


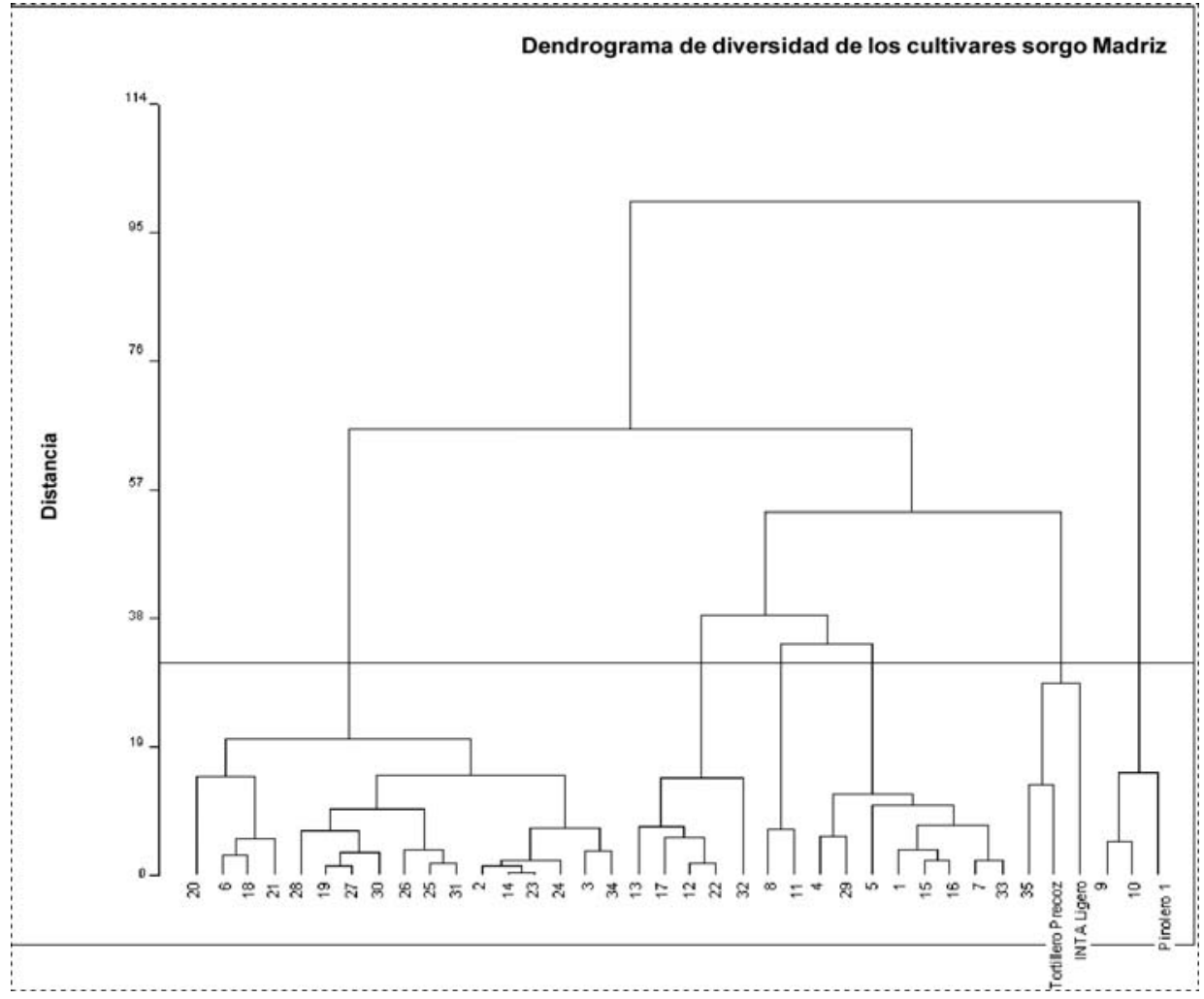

Figura 5. Dendrograma de diversidad morfoagrónomica de 35 cultivares de sorgo tortillero recolectados en siete localidades de Madriz y Estelí, Nicaragua. 2006.

- Grupo de cultivares precoces y porte bajo donde se encuentran las variedades INTA Tortillero Precoz e INTA Ligero más el sorgo crema de Limay, pero este grupo no aparece muy consistente.

Un grupo de dos cultivares (números 8 y 11) aparece bien individualizado y corresponde a versiones acriolladas de CENTA S-2 con las características principales de la variedad original: porte alto, panoja abierta, planta de color púrpura y glumas de color negro y grano grueso.

El grupo $\mathrm{N}^{\circ} 4$, con ocho cultivares reúne los cultivares con mejores rendimientos en rastrojo y granos (alto número de granos por panoja y pesos de mil granos superiores a los 32 gramos); en este grupo encontramos los cultivares Sorgo Ligero (7) y Sorgo Blanco alto (33), que son los mas sembrados en las localidades de Santo Domingo y El Mamel de Totogalpa, respectivamente, y parecen tener un mismo origen. Estos cultivares, con un ligero trabajo de depuración y selección, son interesantes para usar como variedades en esta región y como progenitores de cruzamientos.

Este análisis confirma también que la gran mayoría $(85 \%)$ de las variedades de sorgo tortillero cultivadas y mantenidas por los pequeños productores de la zona: i) tiene otro origen que las variedades liberadas por el INTA o por organizaciones oficiales, ii) presenta bastante diversidad y deja a entender que llegaron a los productores por canales informales.

\section{Una evolución reciente: la sustitución del millón por el sorgo tortillero}

En un periodo de 30-40 años, las áreas sembradas en sorgo en el departamento de Madriz pasaron de $100 \%$ millón hasta un $40 \%$ millón y un $60 \%$ sorgo tortillero. Por supuesto esta evolución no fue igual en todos los municipios del departamento (Figura 6). Por ejemplo el millón ha sido casi abandonado en Palacagüina 


\begin{tabular}{|c|c|c|c|}
\hline \multirow{4}{*}{$\begin{array}{l}\text { Solo millón } \\
\text { en todas las } \\
\text { comunidades }\end{array}$} & \multirow{4}{*}{$\begin{array}{l}\text { Introducción de } \\
\text { las primeras } \\
\text { variedades } \\
\text { precoces (de } \\
\text { sorgo } \\
\text { tortillero) }\end{array}$} & \multirow{4}{*}{$\begin{array}{l}\text { Difusión de las } \\
\text { primeras } \\
\text { variedades de } \\
\text { sorgo blanco } \\
\text { del INTA }\end{array}$} & $\begin{array}{r}\text { Sto Domingo : } \\
\text { Sorgos tortillero y escoba }\end{array}$ \\
\hline & & & $\begin{array}{l}\text { EI Mamel: } \\
\text { Millón indio y sorgo tortillero }\end{array}$ \\
\hline & & & $\begin{array}{l}\text { Uniles: } \\
\text { Especialización en sorgo tortillero }\end{array}$ \\
\hline & & & $\begin{array}{l}\text { La Manzana: } \\
\text { Sorgo tortillero y millón Santa } \\
\text { Cruz }\end{array}$ \\
\hline 1940 & $1970-1975$ & 1985-1995 & 2002 \\
\hline
\end{tabular}

Figura 6. Esquema de evolución de los sorgos en Madriz, Nicaragua (Martínez 2003).

(4\% del área en sorgo) pero se mantiene muy fuerte en San José de Cuzmapa (90\% del área) (Cuadro 7).

\section{Prácticas de selección, multiplicación y conserva- ción de las semillas de sorgo}

En la zona de estudio, $95 \%$ de los productores dijeron que multiplicaban y conservaban su propia semilla de sorgo tortillero y millón para cubrir sus necesidades de siembra del año siguiente. Sin embargo, ellos manejan a menudo esta semilla a "flujo tendido" es decir que conservan sólo la semilla necesaria para una sola siembra (Plessis 2004). En caso que fracase esta siembra por efecto de sequía o ataques de plagas, deben conseguir semilla fuera de la finca; así en 2003, $55 \%$ de los productores de sorgo tortillero

Cuadro 7. Proporción del área sembrada en millón en el área total de sorgo en los municipios sorgueros de Madriz, Nicaragua Nicaragua (Fuente: III CENAGRO, INEC 2002).

\begin{tabular}{lc}
\hline \multicolumn{1}{c}{ Municipios } & $\begin{array}{c}\text { \% del área total de sorgo sembrada } \\
\text { con millón (solo + asociado) }\end{array}$ \\
\hline Telpaneca & 39 \\
Palacagüina & 4 \\
Totogalpa & 44 \\
San Lucas & 52 \\
Yalagüina & 23 \\
Somoto & 33 \\
San José de Cuzmapa & 90 \\
\hline
\end{tabular}

ISSN: 1021-7444 entrevistados utilizaron su propia semilla (de finca) pero $45 \%$ tuvieron que conseguir esta semilla de otro modo (40\% la compraron, $3 \%$ pidieron prestado y $2 \%$ intercambiaron en forma de trueque). Entre los diferentes modos de conseguir semilla afuera, la mitad compró su semilla a otros "buenos" productores de la comunidad, el tercio la compró a comerciantes de grano y $12 \%$ recibieron esta semilla como ayuda. En el caso de los productores de millón, $60 \%$ utilizaron su propia semilla y $40 \%$ tuvieron que comprar su semilla.

Para los sorgos, por lo general, no existe una cultura fuerte de selección de la semilla para mantener la pureza y las cualidades de su(s) variedades o mejorar$\mathrm{la}(\mathrm{s}) ; 80 \%$ de los productores dicen que para usar como semilla seleccionan las panojas de mayor tamaño con los granos más blancos y gruesos pero en mayoría lo hacen después de la cosecha y no toman en cuenta las otras características de la planta. En el caso del sorgo millón, muy a menudo se observan parcelas muy infestadas por el carbón cubierto del grano (Spacelotheca sorghi); lo que significa que los productores no hacen una selección estricta de su semilla en campo, asimismo no conocen y/o no aplican los tratamientos de semilla para controlar esta enfermedad.

\section{Redes de intercambio de semillas de sorgo}

En el estudio realizado en 2003, Justine Plessis ha podido determinar los mecanismos y actores de los intercambios de semillas de sorgo en las seis localidades estudiadas. De este trabajo, la información más sobresaliente es la siguiente: 
- Por su ubicación geográfica pero también por el dinamismo de sus productores, en la localidad de Unile se intercambia bastante semilla dentro de la comunidad y con el exterior; la comunidad recibe semilla de variedades mejoradas de las instituciones (proyecto Libra por Libra del gobierno o donaciones de INTA), compra semilla (grano) en el mercado de Somoto pero sobre todo vende o intercambia semilla con productores de al menos otras seis localidades del departamento.

- En Santo Domingo, los intercambios de semilla se dan dentro de los sectores de la comunidad pero muy poco entre sus sectores. La gran mayoría de los productores suelen comprar semillas en la localidad vecina de San Juan de Somoto con algunos productores dedicados a la producción artesanal de semilla de sorgo que tienen capacidades para depurar y seleccionar semilla en campo.

- Por su ubicación geográfica y proximidad con diferentes instituciones de apoyo, Musuli y la Tranquera reciben a menudo donaciones de semilla de variedades mejoradas; existen muchos intercambios de semillas entre agricultores de la comunidad pero muy poco con productores de otras comunidades.

- En El Mamel, los intercambios de semilla se hacen casi solamente intra-comunidad (por el motivo de aislamiento y solidaridad indígena), hay muy pocos intercambios con el exterior cuando se debe conseguir semilla afuera, compran grano en el mercado de Ocotal.

- En cada localidad, se identificaron los productores claves en los intercambios de semilla de sorgo dentro y afuera de la comunidad.

\section{Objetivos de mejoramiento de los sorgos}

Los objetivos de mejoramiento del millón y sorgo tortillero indicados por los agricultores durante el trabajo de diagnóstico realizado en 2002 son resumidos en el Cuadro 8.

Los agricultores insistieron también sobre otra característica de los sorgos, el problema de "aguate" 15 que causa picazón en el cuerpo, irritación en los ojos

\footnotetext{
15 Polvo de pedazos de florecilla, pluma y arista que quedan suspendidos en el aire durante el desgrane.
}

y hasta problemas respiratorios $y$, por ello buscan variedades que carezcan de dicho carácter.

Para los agricultores los objetivos de mejoramiento propuestos no son alcanzables si no se pone en marcha un programa de capacitación enfatizando los temas siguientes: 1) Identificación, control de plagas y enfermedades del cultivo, 2) Mejoramiento de las técnicas de manejo agronómico (vía intercambios entre productores), 3) Manejo de malezas en las primeras etapas de vida del cultivo, 4) Obtención de semilla de siembra de calidad.

\section{DISCUSIÓN}

\section{Diversidad de los sistemas de cultivo y usos de los sorgos blancos}

Este trabajo confirma que los sorgos blancos, millón y tortillero, son cultivos multipropósito de gran importancia social y económica en la zona.

La diversidad de los sistemas de cultivo responde a la gran diversidad de las condiciones agroecológicas de esta región norte de Nicaragua (topografía, suelos, temperaturas y pluviosidad). Revela también diferencias de estrategias y prioridades de producción entre los sitios y entre los productores de un mismo sitio (Martínez 2003; Plessis 2004). Las asociaciones de cultivo predominantes son una estrategia para reducir los riesgos frente a una pluviosidad irregular y para suplir el déficit de tierra disponible en América Central (Paul et al. 1985). También los asocios de cultivo merman la población de malezas y reducen los trabajos de deshierba (Paul 1990). Es probable que algunos sistemas no tradicionales, como el asocio sorgo tortillero con frijol en primera y rebrote del sorgo en postrera, revela una cierta cultura de innovación impulsada por algunos proyectos en la zona (proyecto experimentación campesina Unicam).

\section{Sustitución rápida del millón por el sorgo tortillero}

Este cambio rápido revela un verdadero dinamismo de los productores de la zona para adaptarse a nuevas condiciones climáticas (sequías más frecuentes y 
Cuadro 8. Objetivos de mejoramiento definidos por los agricultores en la fase de diagnóstico. Madriz, Nicaragua. 2002.

\begin{tabular}{|c|c|c|}
\hline Localidades & ¿Qué mejorar del millón? & ¿Qué mejorar del sorgo tortillero? \\
\hline El Mamel & $\begin{array}{l}\text { 1)* Mejorar el rendimiento: llegar a } 2,1 \mathrm{t} / \mathrm{ha} \mathrm{a}^{* *} \sin \\
\text { fertilizante, en asocio con maíz } \\
\text { 2) Más resistente a las plagas en el almacenamiento } \\
\text { 3) Más resistente a la sequía en la fase de floración y } \\
\text { reducir el tiempo entre la floración y la cosecha } \\
\text { 4) Mejorar la calidad del grano: grano más blanco, } \\
\text { de mayor peso } \\
\text { NB: Mejorar la calidad del rastrojo no es una prioridad }\end{array}$ & $\begin{array}{l}\text { 1) Más resistente a las plagas: chinches y "picudo" } \\
\text { 2) Más resistente a la sequía en la floración } \\
\text { 3) Plantas bajas o con tallos fuertes para resistir al } \\
\text { acame y facilitar la cosecha }\end{array}$ \\
\hline Santo Domingo & $\begin{array}{l}\text { 1) Que sea más ligero, madurez en noviembre y más } \\
\text { resistente al verano } \\
\text { 2) Mejor calidad de rastrojo, más hojas y mejor } \\
\text { calidad } \\
\text { 2) Grano blanco para la tortilla y obtener mejor precio } \\
\text { 2) Más agresivo y resistente a malezas } \\
\text { 3) Altura de dos metros } \\
\text { 3) Más resistente a plagas }\end{array}$ & $\begin{array}{l}\text { 1) Más rápido, menos de } 90 \text { días de la siembra hasta } \\
\text { la cosecha. } \\
\text { 2) Más productivo, con panojas más grandes: } 2 \text { t/ha } \\
\text { 3) Grano más grande y más redondo, de igual peso } \\
\text { que el grano de millón } \\
\text { 4) Mayor producción de rastrojo para la venta } \\
\text { 5) Que sea adaptado a la zona (clima y suelo) }\end{array}$ \\
\hline Unile y La Manzana & $\begin{array}{l}\text { 1) Más rápido (un mes antes), floreciendo a finales } \\
\text { de octubre, que se coseche en diciembre } \\
\text { 1) Resistente a las sequías (en fase vegetativa y flo- } \\
\text { ración) } \\
\text { 2) Color del grano blanco, sin manchas rojas } \\
\text { 2) Altura de planta más baja de dos metros compara- } \\
\text { da a la de las variedades criollas } \\
\text { 3) Más producción de follaje }\end{array}$ & $\begin{array}{l}\text { Unile } \\
\text { 1) Más rápido: } 80 \text { días de la siembra hasta la madurez } \\
\text { 2) Más follaje y más hojas como IRAT } 204 \\
\text { 3) Mejor rendimiento grano: alcanzar los } 1,6 \text { t/ha } \\
\text { 4) Resistencia a la sequía en floración } \\
\text { 5) Resistencia a plagas: chinches, gusanos medidor y } \\
\text { cogollero } \\
\text { 6) Altura de planta = } 1,5 \text { metros } \\
\text { La Manzana } \\
\text { 1) Mayor rendimiento grano: } 2,4 \text { t/ha } \\
\text { 2) Altura de planta más baja (=1 metro) pero con } \\
\text { bastante follaje para el ganado } \\
\text { 3) Aumentar el peso del grano } \\
\text { 4) Resistente a sequía cuando inicia la floración }\end{array}$ \\
\hline
\end{tabular}

* el número indica el grado de prioridad expresado por los productores.

** conversión en t/ha de los objetivos de rendimientos expresados por los agricultores en quintales de libras por manzana o arrobas por manzana.

severas desde1972) y responder a nuevos objetivos de producción (grano de sorgo más consumido, rastrojo más necesario para alimentar los bueyes y el ganado mayor en época de verano). Este resultado muestra una fuerte capacidad de innovación de los agricultores para probar y adoptar nuevas variedades y desarrollar o adaptar sistemas de cultivo que convienen para estas variedades. Este cambio responde a la función "seguridad alimentaria" dado el consumo directo por la familia y el suministro de alimentos, grano y forraje, a los animales de la finca. Por su ciclo corto el sorgo tortillero asegura una cosecha tres meses después de la siembra, así tiene un retorno sobre inversión más rápido.
¿Cómo explicar esta intrusión tan rápida del sorgo tortillero? Los agricultores nos proporcionan tal vez la respuesta a través del nombre que atribuyen a las nuevas variedades de sorgo: entre las 45 variedades recolectadas entre los años 2002 y 2003 , el $70 \%$ tiene en su nombre el calificativo « tortillero »; eso significa que este tipo de sorgo es buscado para la elaboración de tortillas, alimento cotidiano en el campo que tiene una alta importancia nutricional y cultural. Como ya se indicó, por su color más blanco, textura, sabor y aspecto, la tortilla de sorgo tortillero es más parecida a la tortilla de maíz y más atractiva que la tortilla de sorgo millón. En definitiva, podemos concluir que la 
investigación en sorgo ha elaborado variedades de calidad, a tres niveles: i) del punto de vista alimentario humano, ii) agronómicamente y económicamente y iii) ofreciendo un forraje de mejor calidad y palatabilidad en comparación a la del sorgo millón.

Sin embargo, existe una fuerte diferenciación geográfica del equilibrio entre millón y sorgo en las áreas sembradas. El millón predomina todavía en las zonas de laderas y las zonas altas y más frescas de la región donde se adapta mejor que el sorgo tortillero (San José Cuzmapa, Comunidades de Cayantu y Cuje de Totogalpa). Con los ensayos manejados en este proyecto, se ha comprobado que en estas zonas, las variedades existentes de sorgo tortillero crecen mal y tienen un desarrollo atrasado y no compiten en rendimiento con el millón (Trouche et al. 2005). Al contrario, en las zonas bastante planas donde es posible el arado con bueyes y/o con problemas de sequías muy agudos, el sorgo tortillero ocupa casi todo el área (gran parte de Somoto, Palacagüina, Yalagüina, valle de Limay) porque responde mejor, agronómicamente y económicamente, a estas condiciones.

¿El punto de equilibrio sorgo tortillero-millón ya está alcanzado? En nuestra opinión, la respuesta es positiva. Muy probablemente el millón se va a mantener en las parcelas de laderas con fuertes pendientes que no se pueden trabajar con arado, en los suelos más pobres o degradados, y en las zonas altas y frescas, excepto si se logra hacer un trabajo exitoso de mejoramiento genético del tipo tortillero para estas condiciones específicas.

\section{Origen de las variedades de sorgo tortillero adop- tadas en la región}

Los resultados de los estudios de caracterización de las variedades de sorgo recolectadas en la zona indican claramente que más de $80 \%$ de estas variedades no son variedades oficialmente liberadas y no llegaron hacia los productores por los canales formales (oficiales) de difusión. La amplia y rápida difusión del sorgo tortillero en la zona resulta más que todo de un proceso de intercambio informal (monetario u otro) de semillas y granos de campesino a campesino (por los desplazamientos comunes de ellos dentro de la región y las redes sociales asimismo, por las migraciones laborales hacia los países vecinos) y/o de comerciantes a campesinos. Estas variedades desconocidas proceden muy probablemente de El Salvador. Según las observaciones de una muestra de 12 variedades realizadas por investigadores del CENTA en El Salvador, las variedades liberadas CENTA Oriental (liberada en 1989 en la zona Central) y CENTA Jocoro (liberada en 1997 en la ciudad de Jocoro, Oriente) podrían ser las variedades fuentes de varios cultivares recolectados en la zona (Clara 200516).

Sin embargo, este resultado muestra algunas contradicciones. En su mayoría, los productores no tienen un verdadero hábito de selección y conservación a largo plazo de la semilla de sorgo. Sin embargo, algunos productores más expertos y cuidadosos multiplican y conservan las variedades de sorgo tortillero adoptadas en la región para sus necesidades en semillas y/o para vender, y han logrado mantener bastante uniformes estas variedades. Pero a mediano plazo podemos temer una cierta degeneración de estas variedades. Frente a esta situación, las respuestas de los productores son un poco ambiguas: algunos no se preocupan porque para ellos todas las variedades de sorgo tortillero se valen y siempre se podrá conseguir semilla, otros confían en que siempre van a recibir donaciones de semilla del gobierno u ONG.

\section{Producción e intercambios de semillas}

El estudio realizado por Plessis e Izaguirre permitió identificar diferencias entre las comunidades con respecto a la producción y los intercambios de semillas de sorgo; algunas comunidades son más receptoras de semillas, otras más proveedoras, otras casi autónomas. También se identificaron las comunidades junto con los productores más involucrados y dinámicos en cuanto a los intercambios de semillas. Dos comunidades representan casos muy interesantes al respecto: Unile y San Juan de Somoto. En la primera entran de afuera (instituciones y comerciantes) cantidades importantes de semillas de sorgo tortillero y a la vez Unile difunde muchas semillas hacia otras comunidades. San Juan de Somoto es una comunidad especializada en la producción artesanal de semilla de sorgo que abastece a las comunidades vecinas.

\footnotetext{
16 CLARA, R. 2005. Identificación variedades de sorgo tortillero recolectadas en la región de Somoto. CENTA, San Salvador , El Savador (correo electrónico). Comunicación personal.
} 


\section{Objetivos de mejoramiento}

Para los sorgos millón, los objetivos de mejoramiento comunes a las cuatro localidades son: una floración más precoz (para escapar a posibles problemas de sequía de fin del ciclo, asimismo permitir una cosecha en diciembre), una reducción de altura de planta (para resistir al acame y facilitar la cosecha), una mejor calidad de grano para el consumo familiar y la venta (grano más blanco, no manchado, de mayor tamaño y peso volumétrico) y una mayor resistencia a plagas, principalmente a la chinche, los insectos de almacenamiento y la mosquita ${ }^{17}$. Superar los rendimientos de las variedades criollas existentes no aparece como un objetivo muy claro a pesar de ser citado (en general solo pretenden alcanzar los rendimientos potenciales de los millones criollos con mas regularidad). Mejorar la producción y calidad del rastrojo del millón no es un objetivo común en todas las comunidades.

Teniendo como base esta información, el proyecto ha buscado en varias direcciones germoplasma de sorgo sensible al fotoperíodo que podía ajustarse a estos objetivos; esta búsqueda ha permitido encontrar tres fuentes de germoplasma:

- millones mejorados procedentes de una selección masal dentro de las mejores variedades locales en El Salvador buscando un porte más bajo y una mejor productividad (CENTA).

- líneas seleccionadas resultantes de trabajos de retrocruzamientos entre cultivares centroamericanos de millón (utilizados como padres recurrentes), trayendo el carácter sensible al fotoperíodo y el adaptación al medio, y variedades de sorgo insensibles al fotoperíodo de porte bajo y color de planta canela. El objetivo era desarrollar líneas fotosensibles de porte bajo, mejor índice de cosecha, con granos blancos no manchados (proyecto INTSORMIL/EAP Zamorano).

- variedades africanas disponibles en el banco de germoplasma del CIRAD (2000 accesiones) y

\footnotetext{
17 Stenodiplosis (=Contarinia) sorghicola, Coquillet: los productores no mencionaron esta plaga como tal pero hemos comprobado la existencia de esta plaga en la zona.y por experiencia sabemos que los agricultores pueden confundir el vaneamiento (abortos) debidos a ataques de mosquitas con los efectos de la sequía.
}

caracterizadas en Burkina Faso ${ }^{18}$, buscando variedades con posible adaptación, utilizando los criterios de selección siguientes:

En 2002: muestra de 21 variedades floreciendo después del 1 de octubre, con grano blanco o amarillento sin testa y buen comportamiento agronómico;

En 2003: 18 variedades adicionales procedentes de Camerún, Chad o Sudán (mejores orígenes identificadas en 2002) con una fecha de floración después del 15 de octubre, grano blanco o amarillento de buen grosor, altura inferior a los 3,50 m, buen comportamiento agronómico.

Con respecto al sorgo tortillero, los objetivos formulados por los agricultores en las cuatro localidades corresponden a: incrementar el potencial de rendimientos en grano, acortar el ciclo total a 90 días o menos, reducir la altura de planta, ser más tolerante a la sequía en fase de floración, mejorar la resistencia a las plagas y la calidad forrajera (más hojas en la madurez). De manera sorprendente, no resaltan el interés de mejorar la calidad de grano (probablemente los productores están satisfechos de la calidad de grano de las variedades de sorgo que tienen y quizás pensaban que no se puede obtener algo mejor ${ }^{19}$ ). Para responder a los objetivos definidos, el proyecto introdujo variedades y líneas avanzadas desarrolladas por el CIRAD y sus socios en África del oeste (en mayoría de Burkina Faso pero también de Mali, Senegal y Níger) e incorporó también algunas nuevas líneas del INTA.

\section{Consecuencias para la investigación FP}

Dos años después del diagnóstico inicial, con base en los trabajos de evaluación participativa in situ de estas nuevas líneas y variedades de millón y sorgo tortillero, investigadores y campesinos lograron co-seleccionar cultivares promisorios como BF 89-12/1-1-1 y BF 89-18/133-2-1 (tortillero, CIRAD-INERA Burkina), EIME 119 y 99 PREEIME 119 (millón mejorado,

18 Tomando en cuenta que la latitud y pluviosidad de esta región Norte de Nicaragua (entre $13^{\circ}$ y $14^{\circ}$ de latitud norte, $600-800$ $\mathrm{mm})$ se acerca a las de la estación de Saria en Burkina Faso $\left(12^{\circ}\right.$ $38^{\prime} \mathrm{N}, 800 \mathrm{~mm}$ ).

19 Esta apreciación cambió en los años 2003-2004 cuando ellos vieron en las nuevas variedades experimentadas un rango de diversidad de calidades de grano que ellos desconocían hasta la fecha. 
INTSORMIL/EAP Zamorano), PI 569438 y G 1583 (millón, colección CIRAD). En 2005, estos materiales estaban en fase de validación. Estos cultivares promisorios y varios otros evaluados con los productores, fueron utilizados como progenitores de cruzas (por ejemplo, Souroukoukou en millón, variedades locales Sorgo Estopa Negra y Sorgo Ligero). Las descendencias de estas cruzas son utilizadas en los esquemas de fitomejoramiento participativos impulsados con varios grupos de productores mejoradores (siete grupos en seis localidades en 2005). Los resultados de estos últimos trabajos FP serán presentados en una publicación futura.

\section{CONCLUSIONES}

Los estudios de diagnósticos y caracterización de las variedades locales de sorgo recolectadas en el departamento de Madriz demostraron que:

- Hubo en los últimos veinte años un cambio muy importante en las variedades utilizadas y los sistemas de producción de sorgo.

- La realidad del proceso de adopción de variedades mejoradas de sorgo tortillero, que por gran parte no proviene del sistema formal de difusión de variedades liberadas en el país, era desconocido por la investigación nacional y las instituciones locales.

Este contexto de fuerte capacidad de innovación de los agricultores conduciendo a una difusión amplia y eficiente de nuevos tipos de sorgo planteó desde el inicio cuestiones para la investigación. ¿Estas zonas marginales secas, pobres pero dinámicas, constituyen un terreno adecuado para desarrollar un proyecto FP? ¿Se debía iniciar el trabajo con el grano básico menos atendido en la región (el sorgo) para agregar luego otros rubros y temas de investigación participativa a medida que se fortalezcan las alianzas entre actores?. ¿Qué estrategia se debía escoger para desarrollar el proyecto FP sorgo en esta zona? ¿Se debía trabajar solamente sobre el tipo de sorgo moderno y exitoso (tortillero), o sobre los millones antiguos que se mantienen en las condiciones más desfavorables, o considerar ambos tipos y más eventualmente otros (escobero, rojo)?

En definitiva, entre 2002 y 2005 , el proyecto FP CIAT-CIRAD decidió invertir la mayor parte de sus esfuerzos sobre el mejoramiento de los sorgos, considerando tres tipos (tortillero, millón y escobero), y desarrolló las actividades con las orientaciones siguientes:

1. Identificación de las buenas variedades locales de sorgo tortillero, las cuales:

- con un trabajo mínimo de depuración y selección, pueden beneficiar mejor y a más productores: trabajo realizado entre 2003 y 2005 con Sorgo Ligero (Santo Domingo), Sorgo Blanco alto (El Mamel) y Crema (Limay).

- pueden servir como progenitores en cruzas simples y múltiples (creación de poblaciones sintéticas con el gen ms 3 de androesterilidad) utilizadas en esquemas fitomejoramiento participativo o convencional.

2. Énfasis como criterio de primera prioridad en la calidad de grano que sea para el autoconsumo humano (calidad tortillera) o para la venta; a mediano plazo trabajo, los criterios podrán integrar atributos relacionados con la calidad de los productos derivados con una transformación artesanal (rosquetes, atol, pinol).

3. Implementación del FP para los sistemas de cultivo o de producción predominantes (millón-maíz, sorgo solo o con frijol en postrera, sorgo en primera con rebrote) y otros sistemas para generar trabajos e ingresos en época seca (sorgo escobero).

\section{PERSPECTIVAS}

Para el equipo de investigación las perspectivas de continuación de las actividades FP sorgo y los próximos retos a enfrentar son los siguientes:

1. Encontrar las formas adecuadas para valorizar este dinamismo y potencial de innovación campesina lanzando actividades de FP acompañando los esfuerzos impulsados por un conjunto de ONG en la región ${ }^{20}$.

\footnotetext{
${ }^{20} \mathrm{PcaC}$ y su proyecto de biodiversidad de las semillas, Unicam y su proyecto de banco de semillas, CIPRES y su trabajo FP en frijol y maíz.
} 
2. Encontrar los mecanismos adecuados para insertar la tecnología de producción y difusión de semillas de las variedades identificadas o generadas por el proyecto FP en los sistemas y redes informales ya existentes $^{21}$.

3. Aprovechar esta experiencia, y el conocimiento generado, el germoplasma identificado o en vía de desarrollo, los mecanismos y dispositivos operativos implementados para intervenir en otras zonas secas y marginales y así obtener más impacto.

4. Insertar las actividades FP sorgo en un marco interinstitucional más amplio de investigación-acción participativa para los pequeños agricultores de las zonas marginales, abarcando diferentes cultivos de interés y otros temas de investigación complementarios del FP (manejo del cultivo, semillas, transformación y comercialización de los productos).

\section{AGRADECIMIENTOS}

A todos los productores y productoras experimentadores, evaluadores y mejoradores quienes han participado en esta investigación en los diferentes sitios. También agradecemos a los responsables y técnicos de CIPRES, UNICAM, UNAG/PCaC Madriz y ASOPROT quienes han apoyado de una manera $u$ otra en la ejecución de este proyecto, a los ingenieros Rafael Obando y Manual Morales (INTA) por su apoyo a esta investigación y al Ing. René Clara del CENTA El Savador, por su revisión del documento.

\section{LITERATURA CITADA}

CHANTEREAU, J.; VAKSMANN, M.; KOURESSY, M. 1998. Analyse diallele de la réponse photopériodique d'écotypes maliens guinéa de sorgo. In: Bacci L.,

\footnotetext{
${ }^{21}$ Se debe reflexionar de nuevo acerca de la estrategia para escoger: i) estimular a los agricultores para que produzcan su propia semilla de calidad (luego, con las redes informales, la difusión se dará por su propia cuenta), ii) organizar (en cooperativas o otra forma) y capacitar ciertos grupos de productores voluntarios interesados en la producción de semillas de calidad que colocaran en el mercado local, iii) otra forma.
}

Reyniers F.-N. eds. The future of photoperiodical cereals for sustainable production in the semiarid tropics of Africa. CeSIA, Florence, Italy y CIRAD, Montpellier, France. p. 209-224.

GUTIÉRREZ, N.D. 2004. Caracterización del fotoperiodismo y agromorfología de 14 variedades de sorgo millón (Sorghum bicolor [L] Moench) en tres épocas de siembra en el CNIA, Managua. Tesis para obtener el diploma de ingeniero agrónomo generalista de la Universidad Nacional Agraria, Managua, Nicaragua. 51 p.

HOCDÉ, H. 2006. Mejoramiento participativo de cultivos alimentarios en Centro-América: panorama, resultados y retos. Un punto de vista externo. Agronomía Mesoamericana (CR) 17(3): 291-308.

INEC (Instituto Nacional de Estadísticas y Censos) de Nicaragua. 2002. Resultados del Tercer Censo Nacional Agropecuario (III CENAGRO). (en línea). Managua. INEC. Disponible en: http://www.inec.gob.ni (Estadísticas/Censos)

LHOMME, A. 2005. Creating varieties together. A technographic account of partnerships in three Participatory Crop Improvement projects in Nicaragua. Tesis of Master of technology and agrarian development MAKS 18. Wageningen University. 163 p.

MARTÍNEZ , F. 2003. Análisis de los sistemas de cultivo a base de sorgo para la construcción de un programa de mejoramiento genético participativo en el departamento de Madriz, Nicaragua. Tesis de Master of Science en "Développement Agricole Tropical", CNEARC, France. 128 p.

PAUL, C. L. 1990. Agronomía del sorgo. ICRISAT-CLAIS. El Salvador. 240 p.

PLESSIS, J. 2004. Vers la compréhension de la gestion locale des semences de sorgho : une aide à la diffusion des variétés générées par un programme de sélection participative. Etude réalisée dans la zone nord du Nicaragua. Tesis de ingeniero ISTOM, Cergy-Pontoise France. 83 p.

RAPIDEL, B.; RODRÍGUEZ, R.J. 1990. Zonificación agrometeorológica de las lluvias en Nicaragua. CATIE, Turialba, 24p. 
TROUCHE, G.; CHOW, Z.; AGUIRRE, S. 2005. Informe de las actividades en fitomejoramiento participativo de los sorgos en Nicaragua, ciclo agrícola 2004-2005. 24 p.

TROUCHE, G.; HOCDÉ, H.; AGUIRRE S. 2006. Sélection participative des sorghos au Nicaragua : approche et dispositifs. In: Lançon J., Weltzien E., Floquet A. eds. Gestion du partenariat dans les projets de sélection participative. Proceedings de un taller de capacitación organizado del 14 al 18 de marzo del 2005, Cotonou, Benin: 159-173.
TROUCHE, G.; NARVÁEZ ROJAS, L.; CHOW WONG, Z.; CORRALES BLANDÓN, J. 2006. Fitomejoramiento participativo del arroz de secano en Nicaragua: metodologías, resultados y lecciones aprendidas. Agronomía Mesoamericana (CR) 17(3): 307-322.

VAKSMANN, M.; TRAORE, S.; NIANGADO, O.1996. Le photopériodisme des sorghos africains. Agriculture et Développement (FR) 9: 13-18. 